TITLE:

\title{
Observation of positive and negative magneto-LC effects in all- organic nitroxide radical liquid crystals by EPR spectroscopy
}

\section{AUTHOR(S):}

Suzuki, Katsuaki; Uchida, Yoshiaki; Tamura, Rui; Shimono, Satoshi; Yamauchi, Jun

\section{CITATION:}

Suzuki, Katsuaki ... [et al]. Observation of positive and negative magneto-LC effects in allorganic nitroxide radical liquid crystals by EPR spectroscopy. Journal of Materials Chemistry 2012, 22: 6799-6806

\section{ISSUE DATE:}

2012-02-27

\section{URL:}

http://hdl.handle.net/2433/169678

\section{RIGHT:}

(c) The Royal Society of Chemistry 2012; This is not the published version. Please cite only the published version.; この論文は出版社版で ありません。引用の際には出版社版をご確認ご利用ください。 


\title{
Observation of positive and negative magneto-LC effects in all-organic nitroxide radical liquid crystals by EPR spectroscopy
}

\author{
Katsuaki Suzuki, Yoshiaki Uchida, Rui Tamura,* Satoshi Shimono and Jun Yamauchi \\ ${ }_{5}$ Received (in $\left.X X X, X X X\right)$ Xth $X X X X X X X X X 20 X X$, Accepted Xth $X X X X X X X X X 20 X X$
}

DOI: 10.1039/b000000x

The generation of spin glass-like inhomogeneous magnetic interactions (the average spin-spin interaction constant: $\bar{J}>0$ or $\bar{J}<0$ ), which we refer to as positive or negative "magneto-LC effects", respectively, was observed in the bulk liquid crystalline (LC) phases of chiral all-organic radical compounds $\mathbf{2}$ with a positive dielectric anisotropy $(\Delta \varepsilon>0)$ under weak magnetic fields. The sign and magnitude 10 of $\bar{J}$ depended on the type of LC phase or superstructure; stronger positive interactions $(\bar{J}>0)$ operated in the chiral smectic A $\left(\operatorname{SmA}^{*}\right)$ phase of $(2 S, 5 S)-\mathbf{2 b}(89 \% e e)$ than in the chiral nematic $\left(\mathrm{N}^{*}\right)$ phase of $(2 S, 5 S)-\mathbf{2 a}(96 \% e e)$, whereas weak negative interactions $(\bar{J}<0)$ were observed in the achiral nematic $(\mathrm{N})$ phase of $( \pm)$-2a. The origin of the positive magneto-LC effects operating in the SmA* and $\mathrm{N}^{*}$ phases was interpreted in terms of the generation of ferromagnetic head-to-tail spin-spin dipole interactions, whereas antiferromagnetic interactions arising from the formation of the $R S$ magnetic dipolar interaction were responsible for the negative magneto-LC effects in 15 the $\mathrm{N}$ phase.

\section{Introduction}

Liquid crystals (LCs) are unique soft materials that can easily change the molecular orientation or superstructure by the 20 application of external stimuli, such as heat, light and electric or magnetic field, or by adding a chiral dopant, respectively. ${ }^{1-4}$ In this context, paramagnetic liquid crystalline (LC) compounds are fascinating soft materials that can enhance the effect of magnetic fields on the electric, magnetic, and optical properties in LCs. ${ }^{3-11}$

25 In fact, although the possibility of a ferromagnetic LC material had been considered to be unrealistic due to the inaccessibility of long-range spin-spin interactions between rotating molecules in the LC state, ${ }^{4,5}$ quite recently we have found that a sort of spin glass (SG)-like inhomogeneous magnetic interactions (the 30 average spin-spin interaction constant $\bar{J}>0$ ) operate in the bulk $\mathrm{LC}\left(\mathrm{N}, \mathrm{N}^{*}, \mathrm{SmC}\right.$, and $\left.\mathrm{SmC}^{*}\right)$ phases of rod-like all-organic $\mathrm{LC}$ nitroxide radical compounds $\mathbf{1}$ with a negative dielectric anisotropy $(\Delta \varepsilon<0)$ under weak magnetic fields, due most likely to the swift coherent collective properties of organic molecules 35 with structural anisotropy in the LC state. ${ }^{12}$ Furthermore, this observation has proved to have nothing to do with the molecular reorientation effect arising from the simple molecular magnetic anisotropy $(\Delta \chi)$ by means of variable temperature (VT)-EPR spectroscopy.$^{12}$ Thus, we refer to this new magnetic phenomenon 40 as positive "magneto-LC effects" $(\bar{J}>0)$. Remarkably, these radical LC droplets of $\mathbf{1}$ floating on water were attracted to a permanent magnet and moved freely on water under the influence of the magnet, whereas these fully crystallized particles never responded to the same magnet on water. ${ }^{12}$
45 As to the paramagnetic metallomesogens with permanent spins originating from the transition (d-orbital) or lanthanide (f-orbital) metal ion in the mesogen core, such positive magneto-LC effects $(\bar{J}>0)$ have not been observed. ${ }^{13}$ This is most likely because of the highly viscous ligand-coordinated metal complex structure, ${ }^{13}$

50 which is in contrast to the small molecular size of $\mathbf{1}$ responsible for the swift coherent collective behavior of organic molecules in the LC state.

Several other rod-like or discotic all-organic LC nitroxide radical compounds with a DOXYL, TEMPO, or PROYL group 55 as the spin source at the peripheral position in the molecule had been synthesized and magnetically characterized. These achiral rod-like LCs showed no appreciable magnetic interaction, ${ }^{14}$ while the achiral discotic LCs exhibited a weak antiferromagnetic interaction; weak negative magneto-LC effects $(\bar{J}<0) .{ }^{15}$ ${ }_{60}$ Similarly, another achiral discotic LCs with a tris- $(2,4,6-$ trichlorophenyl)methyl radical group in the mesogen core were reported to exhibit strong antiferromagnetic interactions; strong negative magneto-LC effects $(\bar{J}<0) .{ }^{16}$ Thus far, compounds $\mathbf{1}$, which (i) contain a polar and chiral PROXYL unit in the mesogen ${ }_{65}$ core, (ii) are thermally stable up to $150^{\circ} \mathrm{C}$ in the air, and (iii) can show chiral and achiral rod-like LC phases over a wide temperature range below $90^{\circ} \mathrm{C},{ }^{17}$ are only materials that can show positive magneto-LC effects $(\bar{J}>0){ }^{12}$

To clarify the relationship between the sign $(\bar{J}>0$ or $\bar{J}<0)$ 70 and magnitude of magneto-LC effects and the types of rod-like LC phase and molecular structure, we have designed and synthesized compounds 2 with a terminal formyl group, which 
(a)

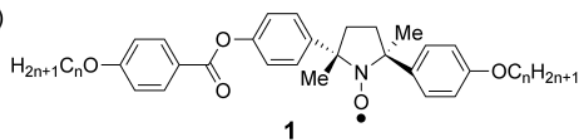

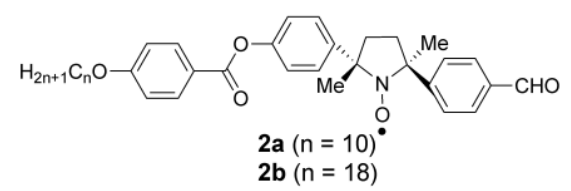

(b)

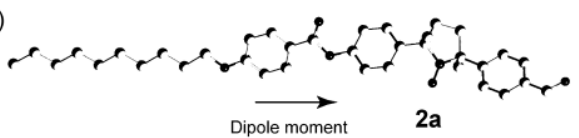

(c)

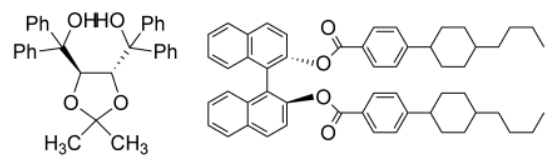

(-)-TADDOL

(S)-BICH

Fig. 1 (a) Molecular structures of compounds $\mathbf{1}$ and 2, (b) the molecular structure of $\mathbf{2 a}(n=10)$ optimized by the AM1 method and the direction of its dipole moment (5.4 Debye), and (c) molecular structures of chiral dopants.

were predicted to have a positive dielectric anisotropy $(\Delta \varepsilon>0)$ by MO calculations (Fig. 1). Here, we report that positive magnetoLC effects $(\bar{J}>0)$ operate in the chiral nematic $\left(\mathrm{N}^{*}\right)$ and smectic A $\left(\mathrm{SmA}^{*}\right)$ phases of $\mathbf{2}$, whereas negative magneto-LC 5 effects $(\bar{J}<0)$ are observed in the achiral nematic $(\mathrm{N})$ phase of 2 . The origin of such different magnetic interactions in the LC phases of $\mathbf{2}$ is discussed on the basis of (i) the temperature dependence of molar magnetic susceptibility $\left(\chi_{\mathrm{M}}\right)$ measured on a SQUID magnetometer and (ii) the temperature dependence of 10 relative paramagnetic susceptibility $\left(\chi_{\text {rel }}\right), g$-value, and peak-topeak line width $\left(\Delta H_{\mathrm{pp}}\right)$ obtained by EPR spectroscopy, which has proved to be an excellent tool to analyze the magnetic interactions operating in the LC phases of all-organic nitroxide radical compounds. ${ }^{12}$

15

\section{Experimental}

\section{General}

Unless otherwise noted, solvents and reagents were reagent grade and used without further purification. THF which is used for 20 electron paramagnetic resonance (EPR) spectroscopy or Grignard reactions was distilled from sodium/benzophenone ketyl under argon. Phase transition temperatures were determined by differential scanning calorimetry (DSC) analysis at the scanning rate of $5^{\circ} \mathrm{C} \min ^{-1}$ (SHIMADZU DSC-60) and polarized optical 25 microscopy (Olympus BHSP). Hot stage (JHC TH-600PH) was used as the temperature control unit for microscopy. IR spectra were recorded with SHIMADZU IRPrestige-21. EPR spectra were recorded with a JEOL FE1XG. HPLC analysis was carried out by using a chiral stationary phase column (Daicel Chiralcel $\left.{ }_{30} \mathrm{OD}-\mathrm{H}, 0.46 \times 25 \mathrm{~cm}\right)$, a mixture of hexane and 2-propanol (9:1) as the mobile phase at the flow rate of $1.0 \mathrm{~mL} / \mathrm{min}$, and a UV-vis spectrometer $(254 \mathrm{~nm})$ as the detector (Fig. S1, ESI $\dagger$ ).

\section{Derivation of relative paramagnetic susceptibility $\left(\chi_{\text {rel }}\right)$ ${ }_{35}$ from EPR spectra}

The EPR spectra of $\mathbf{2 a}$ and $\mathbf{2 b}$ in the solid and LC states measured at a magnetic field of $0.33 \mathrm{~T}$ (X-band) by using a quartz tube $(5 \mathrm{~mm} \phi)$ were Lorentzian in an ambient temperature range (Fig. S2-S4, ESI $\dagger$ ). Therefore, by using the parameters

${ }_{40}$ directly obtained from the differential curves, such as maximum peak height $\left(I_{\mathrm{m}}^{\prime}\right.$ and $\left.-I_{\mathrm{m}}^{\prime}\right), g$-value $(g)$ and peak-to-peak line width $\left(\Delta H_{\mathrm{pp}}\right)$, paramagnetic susceptibility $\left(\chi_{\text {para }}\right)$ could be derived from the following Bloch equation. ${ }^{18}$

$$
\chi_{\text {para }}=2 \mu_{\mathrm{B}} g I_{\mathrm{m}} \Delta H_{\mathrm{pp}}^{2} /\left(\sqrt{3} h v H_{1}\right)
$$

45 where $\mu_{\mathrm{B}}$ is Bohr magneton, $h$ is Planck's constant, $v$ is the frequency of the absorbed electromagnetic wave, and $H_{1}$ is the amplitude of the oscillating magnetic field. For plotting the temperature dependence of $\chi_{\text {para }}$, the relative paramagnetic susceptibility $\left(\chi_{\text {rel }}\right)$, which is defined as

${ }_{50} \chi_{\text {rel }}=\chi_{\text {para }} / \chi_{0}$

where $\chi_{0}$ is the standard paramagnetic susceptibility at $30^{\circ} \mathrm{C}$ in the heating run, was used in place of $\chi_{\text {para }}$ to simplify the treatment. The magnetic data are the mean values of five measurements at each temperature to estimate $\chi_{\text {para }}$ with 55 maximum accuracy.

\section{Results and Discussion}

\section{Characterization of LC Phases of 2}

60

The LC phases of $\mathbf{2}$ were characterized by DSC analysis, polarized optical microscopy (POM), and VT-XRD analysis (Fig. 2-4 and S5, ESI $\dagger)$. Enantiomerically enriched (2S,5S)-2a (96\% ee) showed an enantiotropic $\mathrm{N}^{*}$ phase between 75 and $106^{\circ} \mathrm{C}$ in
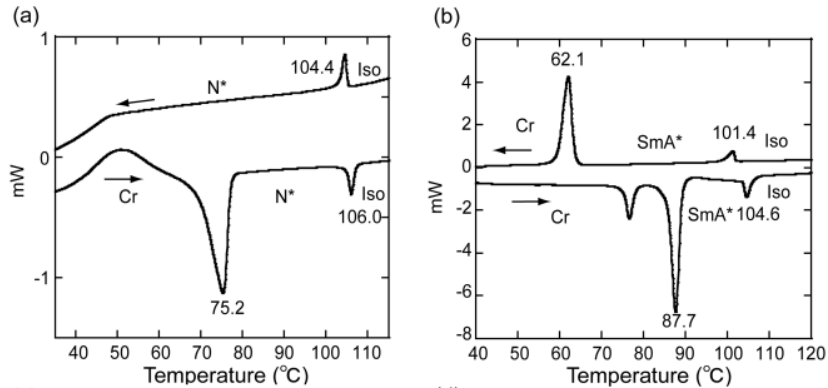

(c)

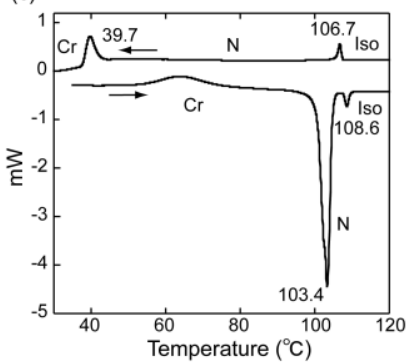

(d)

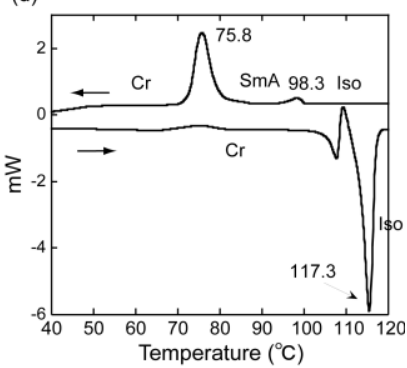

Fig. 2 DSC curves of (a) $(2 S, 5 S)-\mathbf{2 a}(96 \%$ ee $)$, (b) $(2 S, 5 S)-\mathbf{2 b}$ $(89 \% e e),(c)( \pm)-\mathbf{2} \mathbf{a}$, and (d) ( \pm )-2b. Panels a, b, and d refer to the first heating and cooling runs, while panel $\mathrm{c}$ refers to the second heating and cooling runs. 
(a)

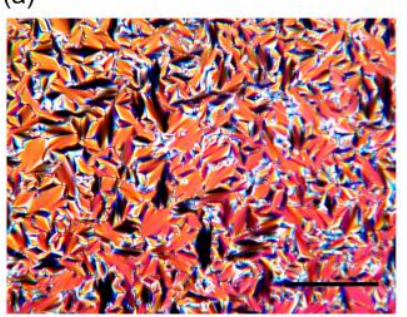

(b)

(c)

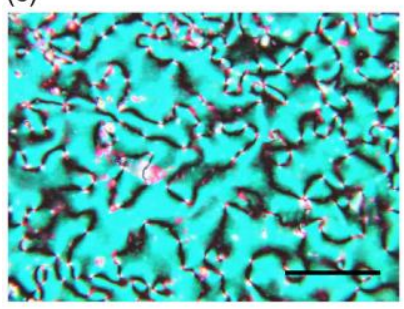

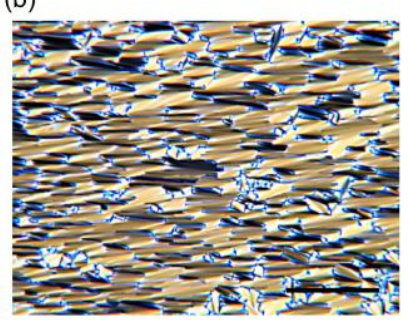

(d)

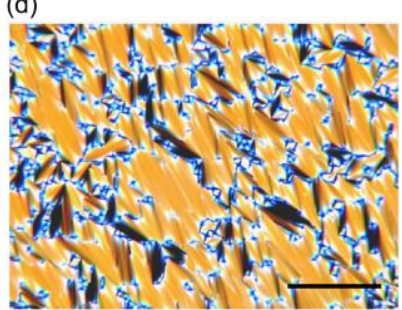

Fig. 3 Polarized optical microphotographs of $\mathbf{2} \mathbf{a}$ and $\mathbf{2 b}$ in the cooling run. (a) A fan-like texture for the $\mathrm{N}^{*}$ phase of $(2 S, 5 S)$ 2a $(96 \%$ ee $)$ at $95^{\circ} \mathrm{C}$. (b) a fan-shaped texture for the $\mathrm{SmA}^{*}$ phase of $(2 S, 5 S)-2 \mathbf{b}(89 \% e e)$ at $80^{\circ} \mathrm{C}$. (c) a Schlieren texture for the $\mathrm{N}$ phase of $( \pm)-\mathbf{2 a}$ at $98^{\circ} \mathrm{C}$. (d) a fan-shaped texture for the $\mathrm{SmA}$ phase of $( \pm)-\mathbf{2 b}$ at $98^{\circ} \mathrm{C}$. Panels a, b, and $\mathrm{d}$ show the textures observed under homogeneous planar boundary conditions in a thin sandwich cell ( $4 \mu \mathrm{m}$ thickness), while panel $\mathrm{c}$ is the natural texture. The scale bar at the lower right in each photograph corresponds to $100 \mu \mathrm{m}$.

the heating run and between 104 and $<30^{\circ} \mathrm{C}$ in the cooling run (Fig. 2a, 3a, 4, and S5a, ESI $\dagger$ ), while $(2 S, 5 S)-2 b(89 \% e e)$ exhibited exclusively an enantiotropic $\mathrm{SmA}^{*}$ phase between 88 and $105^{\circ} \mathrm{C}$ in the heating run and between 101 and $62^{\circ} \mathrm{C}$ in the 5 cooling run (Fig. 2b, 3b, 4, and S5b, ESI $\dagger$ ). As for the corresponding racemic samples, $( \pm)$-2a showed an enantiotropic $\mathrm{N}$ phase between 103 and $109^{\circ} \mathrm{C}$ in the second heating run and between 107 and $40^{\circ} \mathrm{C}$ in the cooling run (Fig. 2c, 3c, 4, and S5c, ESI $\dagger)$, whereas $( \pm)-\mathbf{2 b}$ exhibited a monotropic SmA phase 10 between 98 and $76^{\circ} \mathrm{C}$ only in the cooling run (Fig. 2d, 3d, 4, and $\mathrm{S} 5 \mathrm{~d}, \mathrm{ESI} \dagger)$; this LC temperature range became so narrow due to the undesired crystallization occurring at slower cooling rates than $5^{\circ} \mathrm{C} \min ^{-1}$ that the magnetic data for the SmA phase of $( \pm)$ -

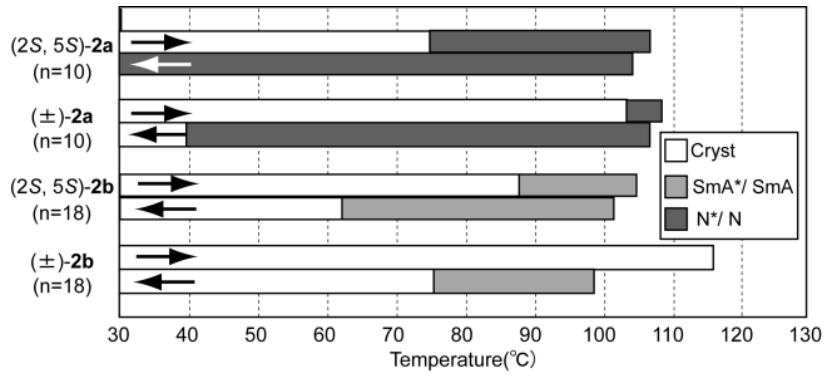

Fig. 4 LC behaviors of $\mathbf{2 a}$ and $\mathbf{2 b}$. Transition temperatures were determined by DSC analysis at the scanning rate of $5^{\circ} \mathrm{C}$ $\min ^{-1}$ and POM in the first heating (upper bar) and cooling (lower bar) runs for $(2 S, 5 S)-\mathbf{2 a}(96 \%$ ee $),(2 S, 5 S)$-b $(89 \%$ ee $)$ and $( \pm)-\mathbf{2 b}$ and in the second heating (upper bar) and cooling (lower bar) runs for $( \pm)-\mathbf{2 a}$.

2b could not be obtained. Since the calculated molecular length 15 (43.2 $⿱$ A) of $\mathbf{2 b}$ is shorter than those (51.7 and $50.8 \AA$ ) obtained from the XRD analyses of $(2 S, 5 S)-\mathbf{2 b}$ and ( \pm )-2b (Fig. S5b,d, ESI $\dagger$ ), it is anticipated that both the $\mathrm{SmA}^{*}$ and SmA phases assume a deeply interdigitated molecular arrangement (see Fig. $12 \mathrm{~d})$. Thus, we could collect the magnetic data for the stable 20 enantiotropic $\mathrm{N}^{*}, \mathrm{~N}$, and $\mathrm{SmA} *$ phases of $(2 S, 5 S)-\mathbf{2 a},( \pm)-\mathbf{2 a}$, and $(2 S, 5 S)-\mathbf{2 b}$, respectively.

\section{SQUID Magnetometry}

25 To confirm that the magnetic behavior in the magnetic LC phases is different from that in their crystalline phases and to prove which magnetic interactions are operative in each LC phase, $\bar{J}>$ 0 or $\bar{J}<0$, we measured the temperature dependence of $\chi_{\mathrm{M}}$ for the above three samples at a magnetic field of 0.05 or $0.5 \mathrm{~T}$ (Fig. $\left.{ }_{30} \mathrm{~S} 6-\mathrm{S} 8, \mathrm{ESI}+\right)$. Here we define the sum of $\chi_{\text {para }}$ and $\chi_{\text {dia }}$ as molar magnetic susceptibility $\left(\chi_{\mathrm{M}}=\chi_{\text {para }}+\chi_{\text {dia }}\right)$, because we cannot exactly determine the paramagnetic susceptibility $\left(\chi_{\text {para }}\right)$ in the magnetic LC phases due to the temperature-dependent nature of diamagnetic susceptibility $\left(\chi_{\text {dia }}\right)$ in LC phases. ${ }^{19,20}$ The $\chi_{\mathrm{M}}-T$ plots 35 obeyed the Curie-Weiss law in the temperature range between 200 and $300 \mathrm{~K}\left[\chi_{\mathrm{M}}=C /(T-\theta)+\chi_{\mathrm{dia}}\right.$ : Weiss constants $\theta=-0.5$, 7.3, and $-1.1 \mathrm{~K}$ and Curie constants $C=0.36,0.38$, and 0.36 e.m.u. $\mathrm{K} \mathrm{mol}^{-1}$ for $(2 S, 5 S)-\mathbf{2 a}, \quad( \pm)-\mathbf{2 a}$, and $(2 S, 5 S)-\mathbf{2 b}$, respectively, at $0.5 \mathrm{~T}$ ] (Fig. S6c, S7c, and S8c, ESI $\dagger$ ), exhibiting 40 the magnetic properties of ordinary paramagnetic radical crystals with weak antiferromagnetic interactions at low temperatures. On the contrary, between 25 and $120^{\circ} \mathrm{C}$, we observed a considerable $\chi_{\mathrm{M}}$ increase $(\bar{J}>0)$ for $(2 S, 5 S)$-2a and $(2 S, 5 S)$-2 b and a slight $\chi_{\mathrm{M}}$ decrease $(\bar{J}<0)$ for $( \pm)-\mathbf{2 a}$ at the Cr-to-LC phase transition 45 in the heating run (Fig. S6a,b, S7a,b, and S8a,b, ESI $\dagger$ ). Since the scatter of the $\chi_{\mathrm{M}^{-}} T$ plots for $\mathbf{2 a}$ and $\mathbf{2} \mathbf{b}$ at higher temperatures was too large to discuss the details of the temperature dependence of the magnetic interactions (Fig. S6-S8, ESI $\dagger$ ) and it was impossible to accurately estimate the $\chi_{\text {para }}$ values in the magnetic ${ }_{50} \mathrm{LC}$ phases due to the variable $\chi_{\text {dia }}$, we have used the relative paramagnetic susceptibility $\left(\chi_{\text {rel }}\right)$ value by EPR spectroscopy which allows us to ignore the $\chi_{\text {dia }}$ term, according to our previous work. $^{12}$

\section{${ }_{55}$ EPR Spectroscopy}

The temperature dependence of EPR spectra of $(2 S, 5 S)-\mathbf{2 a},( \pm)-\mathbf{2 a}$, and $(2 S, 5 S)-\mathbf{2} \mathbf{b}$ in the solid and LC states was measured between 30 and $120^{\circ} \mathrm{C}$. Although these magnetic data revealed the same 60 tendency as those obtained by SQUID magnetization measurement (Fig. S6-S8, ESI $\uparrow$ ), those obtained by EPR spectroscopy could distinctly display a more detailed change in $\chi_{\text {para }}$ with full reproducibility. The temperature dependence of relative paramagnetic susceptibility $\left(\chi_{\text {rel }}\right)$ is shown in Fig. 5 (See ${ }_{65}$ Experimental section for the definition of $\left.\chi_{\text {rel }}\right)$.

Indeed, $(2 S, 5 S)-\mathbf{2 a}(96 \%$ ee $)$ exhibited an explicit $\chi_{\text {rel }}$ increase (positive magneto-LC effects, $\bar{J}>0$ ) by 0.13 at the Cr-to-N* phase transition $\left(75^{\circ} \mathrm{C}\right)$ in the heating run (Fig. 5a), while ( \pm )-2a showed a small but a distinct $\chi_{\text {rel }}$ decrease (negative magneto-LC 70 effects, $\bar{J}<0)$ by 0.05 at the Cr-to-N transition $\left(104^{\circ} \mathrm{C}\right)$ in the heating run (Fig. 5d). These results suggest that the formation of 
(a)

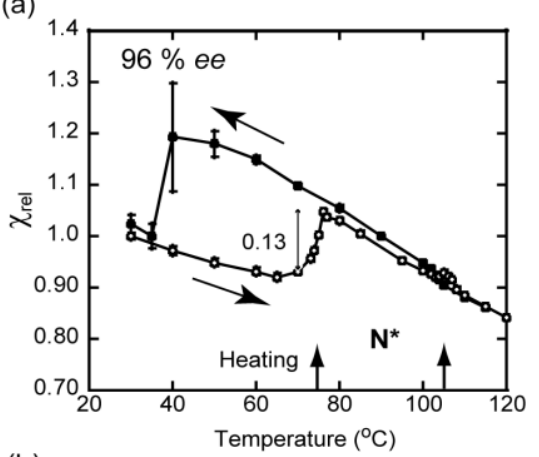

(b)

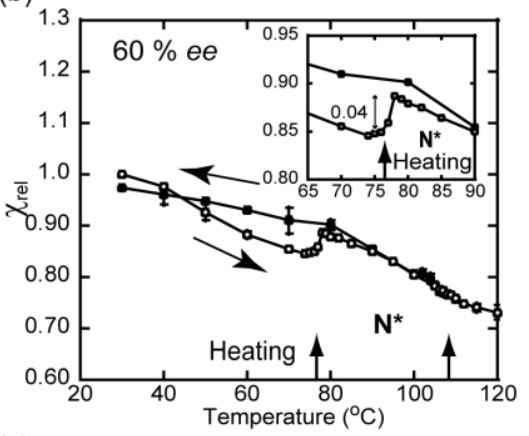

(c)

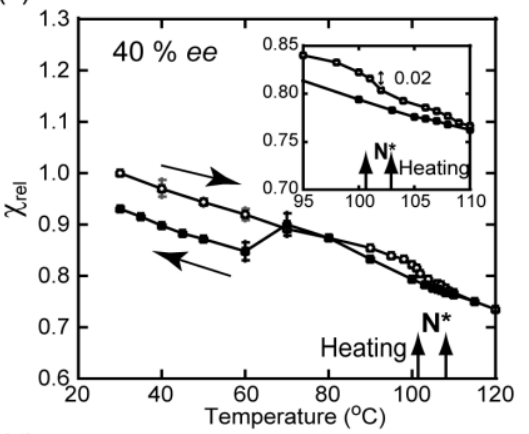

(d)

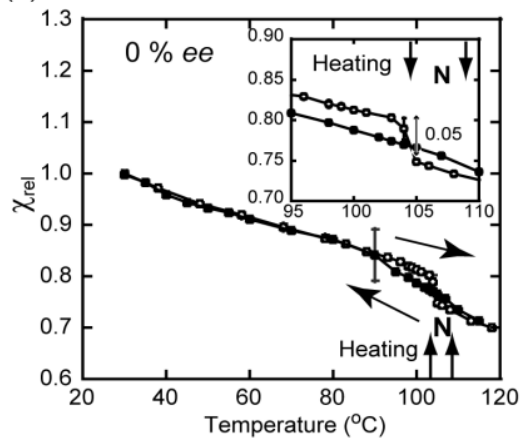

Fig. 5 Temperature dependence of $\chi_{\text {rel }}$ value for $\mathbf{2 a}$ at a magnetic field of $0.33 \mathrm{~T}$. (a) $(2 S, 5 S)-\mathbf{2 a}(96 \% e e)$, (b) $(2 S, 5 S)-$ 2a $(60 \% e e),(\mathrm{c})(2 S, 5 S)-\mathbf{2 a}(40 \% e e)$, and (d) ( \pm )-2a. The LC temperatures determined by DSC analysis in the heating run are shown in the lower sides inside panels. The insets indicate the magnification of $\chi_{\text {rel }}$ vs $T$ plots. The LC temperatures inside the insets refer to the heating run.

either a non-helical superstructure or an $R S$ magnetic dipolar interaction should be responsible for the generation of the weak negative magneto-LC effects, or weak antiferromagnetic interactions, in the $\mathrm{N}$ phase of $( \pm)-\mathbf{2 a}$.

5 To prove this hypothesis and evaluate the relationship between the sign and magnitude of magneto-LC effects and the helical pitch length, a chiral dopant was added to ( \pm )-2a to prepare a racemic helical $\mathrm{N}^{*}$ phase. $(S)$ - $\mathrm{BICH}$ was found to be a more powerful chiral dopant than (-)-TADDOL to induce an $\mathrm{N}^{*}$ phase 10 of $( \pm)-2 \mathbf{a}$; addition of 2.5 or $4.0 \mathrm{wt} \%$ of $(S)-\mathrm{BICH}$ to $( \pm)-\mathbf{2 a}$ induced a $\mathrm{N}^{*}$ phase with the pitch length of 1.8 or $1.1 \mu \mathrm{m}$ at $100^{\circ} \mathrm{C}$, respectively (Fig. 6 and S9e,f, ESI $\dagger$ ), while $5 \mathrm{wt} \%$ of (-)TADDOL led to that of $8 \mu \mathrm{m}$ at $80^{\circ} \mathrm{C}$ (Fig. S9d, ESI $\dagger$ ). Consequently, almost no influence of chiral dopants, or the 15 helical pitch length, on the magneto-LC effects was noted (Fig. 7).

Next, to clarify the effects of the ee value of $\mathbf{2 a}$ on the sign and magnitude of magneto-LC effects, the temperature dependence of EPR spectra of 2a with $40 \%$ ee and $60 \%$ ee was measured. As the $e e$ value decreased, the helical pitch elongated (Fig. 6 and S9a-c, ${ }_{20} \mathrm{ESI} \dagger$ ). As a consequence, a $\chi_{\text {rel }}$ increase (positive magneto-LC effects) by 0.04 at the $\mathrm{Cr}$-to- $\mathrm{N}^{*}$ transition $\left(77^{\circ} \mathrm{C}\right)$ was noted in the $\mathrm{N}^{*}$ phase (the pitch length of $1.2 \mu \mathrm{m}$ at $80^{\circ} \mathrm{C}$ ) of $60 \%$ ee in the heating run (Fig. 5b), while the $\mathrm{N}^{*}$ phase (the pitch length of 1.6 $\mu \mathrm{m}$ at $100^{\circ} \mathrm{C}$ ) of $40 \%$ ee showed a $\chi_{\text {rel }}$ decrease (negative 25 magneto-LC effects) by 0.02 at the Cr-to-N* transition $\left(102^{\circ} \mathrm{C}\right)$ in the heating run (Fig. 5c). These results indicate that as the ee value increases, the $R S$ magnetic dipolar interaction reduces in the $\mathrm{N}^{*}$ phase and thereby the positive magneto-LC effects turn out to prevail over the negative ones.

30 Thus, the origin of the negative magneto-LC effects observed in the $\mathrm{N}$ phase could be understood in terms of the formation of the $R S$ magnetic dipolar interaction due to the strong electric dipole interactions $(\Delta \varepsilon>0)$, which results in the generation of weak anitiferromagnetic interactions, even in the chiral dopant35 induced racemic helical $\mathrm{N}^{*}$ phase.

In the case of $(2 S, 5 S)-\mathbf{2 b}(89 \% e e)$, during the heating process, the $\chi_{\text {rel }}$ increased by as large as 0.20 at the $\mathrm{Cr}$-to-SmA* transition $\left(87^{\circ} \mathrm{C}\right)$ and by additional 0.07 at the $\mathrm{SmA} *$-to-Iso transition $\left(104^{\circ} \mathrm{C}\right)$ (Fig. 8a). The $\chi_{\text {rel }}$ values in the $\mathrm{SmA}^{*}$ phase of $(2 S, 5 S)$ -

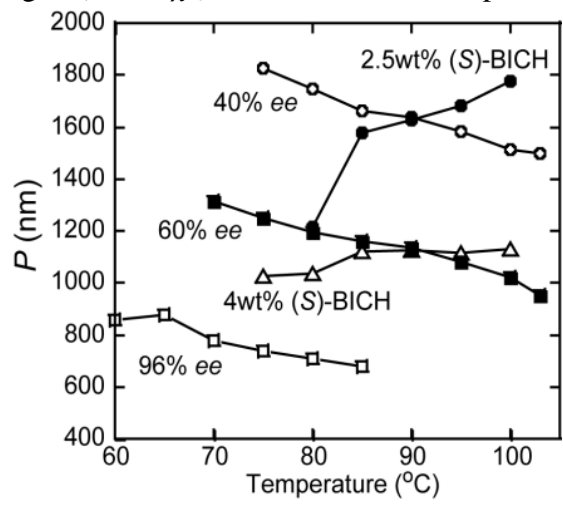

Fig. 6 Temperature dependence of helical pitch length measured by using a wedge cell in the cooling run. Open and filled squares, and open circles correspond to $(2 S, 5 S)$-enriched 2a of $96 \% e e, 60 \% e e$, and $40 \% e e$, respectively. Filled circles and open triangles denote $( \pm)-2 a$ doped with 2.5 and $4.0 \mathrm{wt} \%$ of $(S)$-BICH, respectively. 
2b in the cooling run were much larger than those in the heating run, implying the large difference in the magnetic interactions in the same $\mathrm{SmA}^{*}$ phase between the two processes. This unusual magnetic behavior in the $\mathrm{SmA}^{*}$ phase of $(2 \mathrm{~S}, 5 \mathrm{~S})-\mathbf{2 b}$ can be 5 explained by the difference in the LC domain size between the heating and cooling runs (Fig. 9c); the larger the domain size, the larger the magnetic interactions. ${ }^{12}$ Meanwhile, as expected, almost no difference in the domain size was noted between the heating and cooling runs in the $\mathrm{N}^{*}$ and $\mathrm{N}$ phase of $\mathbf{2 a}$ (Fig. 9a,b).

(a)

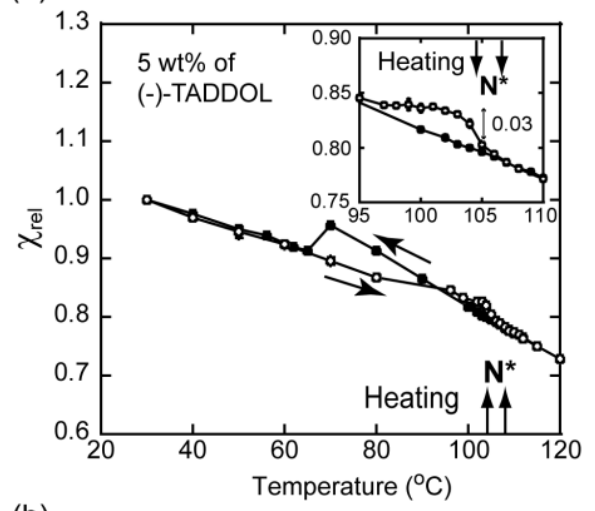

(b)

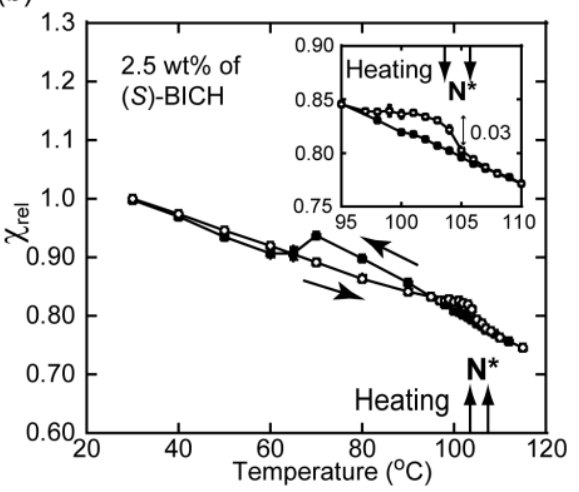

(c)

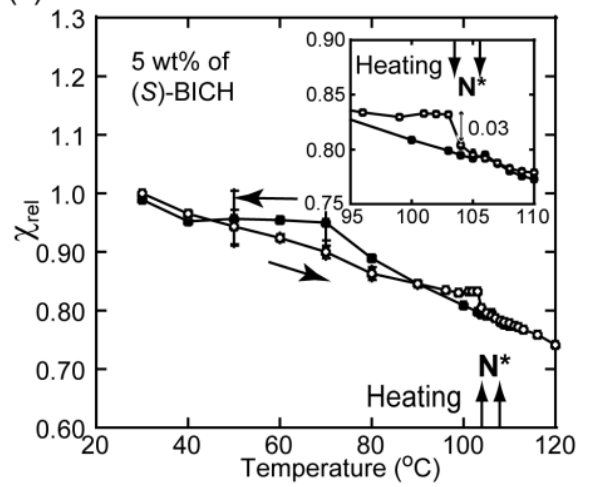

Fig. 7 Temperature dependence of $\chi_{\text {rel }}$ value for $( \pm)-\mathbf{2 a}$ in the presence of a chiral dopant at a magnetic field of $0.33 \mathrm{~T}$. (a) 5 wt $\%$ of (-)-TADDOL, (b) $2.5 \mathrm{wt} \%$ of $(S)-\mathrm{BICH}$, and (c) 4.0 wt $\%$ of $(S)-\mathrm{BICH}$. The LC temperatures determined by DSC analysis in the heating run are shown in the lower sides inside panels. The insets indicate the magnification of $\chi_{\text {rel }}$ vs $T$ plots. The LC temperatures inside the insets refer to the heating process.
10 Thus, in the heating run, $(2 S, 5 S)-\mathbf{2 a}(96 \% e e)$ and $(2 S, 5 S)-\mathbf{2 b}$ ( $89 \%$ ee) showed a considerable net $\chi_{\text {rel }}$ increase $(0.13$ and 0.20 ) at the Cr-to-N* and $\mathrm{Cr}$-to-SmA* phase transitions, respectively (Fig. 5a and 8a), whereas ( \pm )-2a exhibited a small but distinct $\chi_{\text {rel }}$ decrease (0.05) at the Cr-to-N phase transition (Fig. 5d). In other 15 words, larger positive magneto-LC effects $(\bar{J}>0)$ operated in the $\mathrm{SmA}^{*}$ phase of $(2 S, 5 S)-\mathbf{2} \mathbf{b}$ than in the $\mathrm{N}^{*}$ phase of $(2 S, 5 S)-\mathbf{2} \mathbf{a}$, whereas small negative magneto-LC effects $(\bar{J}<0)$ was noted in the $\mathrm{N}$ phase of $( \pm)-\mathbf{2 a}$, compared to their crystalline phases. It is noteworthy that the $\chi_{\text {rel }}$ value of 1.4 observed in the SmA* 20 phase of $(2 S, 5 S)$-2 $\mathbf{b}$ in the cooling run is the largest of all magnetic LC phases of $\mathbf{1}$ and $\mathbf{2}$ (Fig. 8a). ${ }^{12}$

(a)

(b)
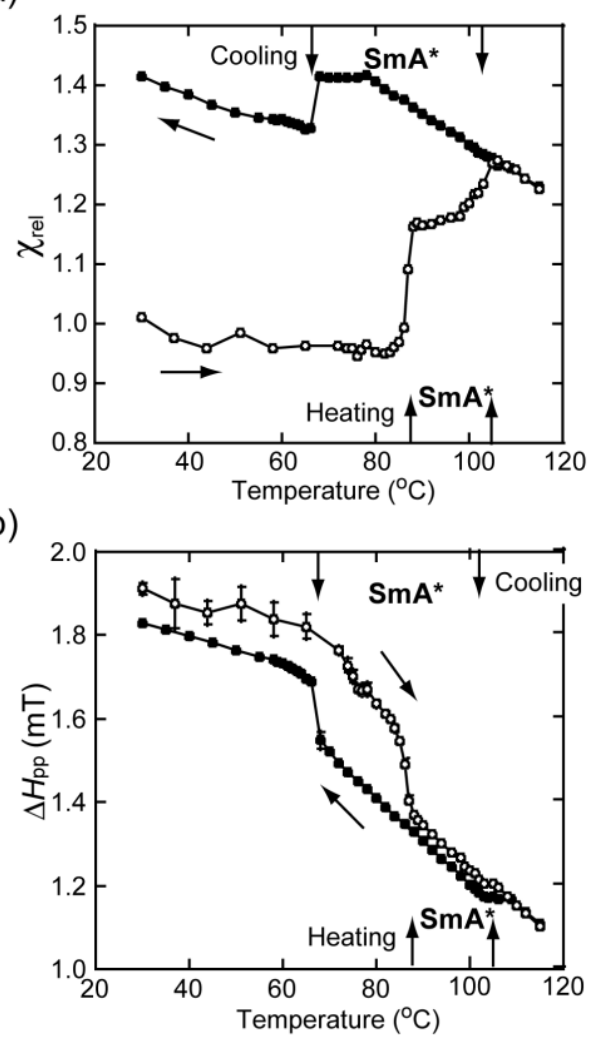

(c)

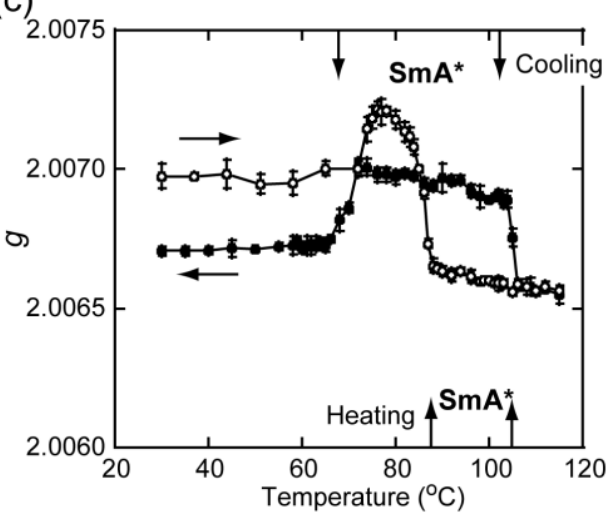

Fig. 8 Temperature dependence of (a) $\chi_{\text {rel }}$, (b) $\Delta H_{\text {pp }}$, and (c) $g$ values for $(2 S, 5 S)-\mathbf{2 b}(89 \% e e)$ by EPR spectroscopy at a magnetic field of $0.33 \mathrm{~T}$. The $\mathrm{LC}$ temperatures determined by DSC analysis in the heating and cooling runs are shown in the lower and upper sides inside panels, respectively. 
(a) Heating

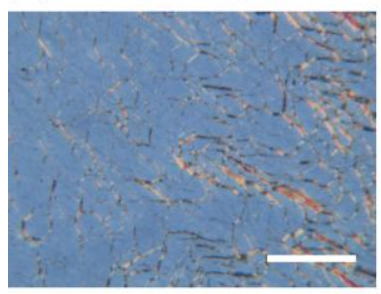

(b)
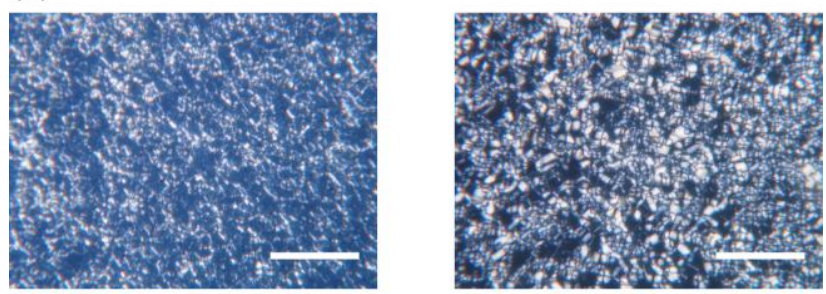

(c)
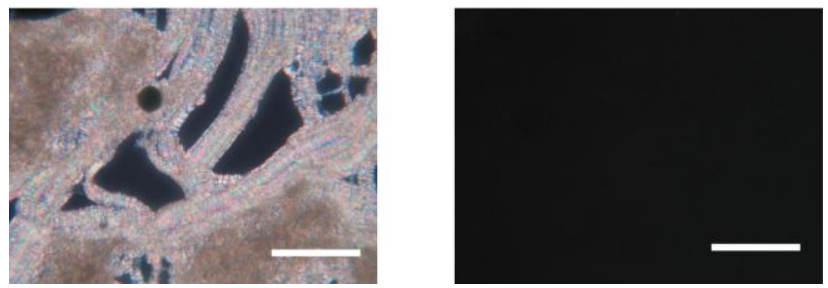

Fig. 9 Comparison of individual LC textures of $\mathbf{2 a}$ and $\mathbf{2 b}$ between the heating (left) and cooling (right) processes. (a) An oily-streaks texture for the $\mathrm{N}^{*}$ phase of $(2 S, 5 S)$-2a $(96 \%$ ee $)$ at $90^{\circ} \mathrm{C}$; (b) a Schlieren texture for the $\mathrm{N}$ phase of $( \pm)-\mathbf{2 a}$ at $104^{\circ} \mathrm{C}$; (c) a multi-domains texture (left) and a homeotropically-aligned pseudo-isotropic texture (right) of the SmA* phase of $(2 S, 5 S)-2 \mathbf{b}(89 \% e e)$ at $95^{\circ} \mathrm{C}$. Polarized optical microphotographs were taken for the natural textures. The scale bar at the lower right in each photograph corresponds to $100 \mu \mathrm{m}$.

Meanwhile, for the above three samples, a very small or no change in the $\chi_{\text {rel }}$ value was noted at the Iso-to-LC phase transition in the cooling run, implying the fair similarity in the magnetic local structure between the LC and isotropic phases to 5 hold analogous magnetic interactions, similarly to the case of compounds $\mathbf{1} .^{12}$

\section{Response of LC Droplets on Water to the Action of a Permanent Magnet}

To compare the extents of magneto-LC effects in these three LC phases visually, we watched how individual LC droplets and crystallized particles of $(2 S, 5 S)-\mathbf{2 a}(96 \% e e),( \pm)-\mathbf{2 a}$, and $(2 S, 5 S)$ $\mathbf{2 b}(89 \%$ ee) on water behaved under the influence of a permanent 15 magnet. The LC droplet with a diameter of $1 \sim 5 \mathrm{~mm}$ was prepared by floating the melted $\mathrm{LC}$ compound on hot water at $75^{\circ} \mathrm{C}$ by using a small plastic spatula. Generally, a sufficiently strong magnet can attract any paramagnetic materials. As an ordinary rod-like rare-earth magnet (maximum $0.5 \mathrm{~T}, 6 \mathrm{~mm} \phi \times 20 \mathrm{~mm}$ ) 20 approached (Fig. S10, ESI + ), the respective $\mathrm{N}^{*}$ and $\mathrm{SmA}^{*}$ droplets of $(2 S, 5 S)-\mathbf{2 a}$ and $(2 S, 5 S)-\mathbf{2} \mathbf{b}$, and the partially crystallized $\mathrm{N}$ droplet of $( \pm)$-2a floating on water were explicitly attracted by both the $\mathrm{N}$ and S poles of the magnet (Movies S1-S3), while these fully crystallized particles on water never responded 25 to the same magnet. This behavior was fully reproducible, indicating that the threshold magnetic field required to attract crystalline paramagnetic particles by the magnet is much larger than that required for attracting magnetic LC droplets due to the increasing interfacial interaction between the crystalline particle 30 and water.

Interestingly, the $\mathrm{SmA}^{*}$ droplet of $(2 S, 5 S)-\mathbf{2 b}$ responded to the action of the magnet more quickly than the $\mathrm{N}^{*}$ droplet of $(2 S, 5 S)-\mathbf{2 a}$, while the partially crystallized $\mathrm{N}$ droplet of $( \pm)-\mathbf{2 a}$ moved very slowly (Movies S1-S3). These results suggest that 35 the difference in the response of these LC droplets to the magnet should depend not only on the interfacial interaction between the LC droplet and water but also on the sign and magnitude of (a)

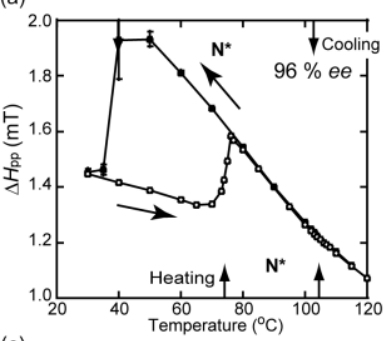

(c)
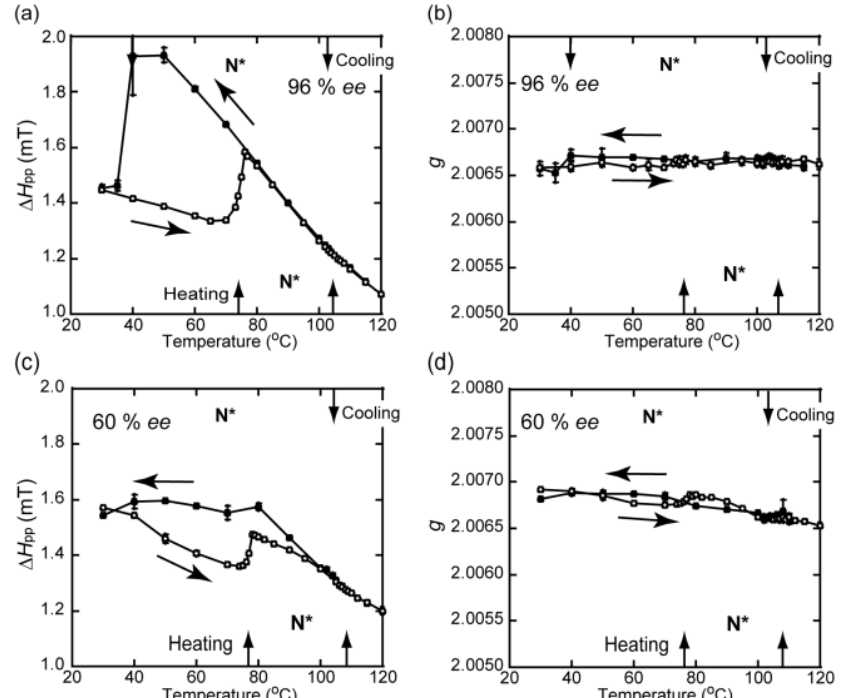

(d)

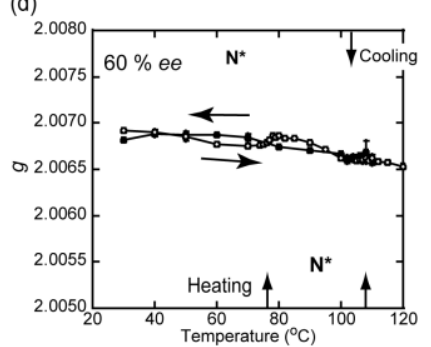

(e)

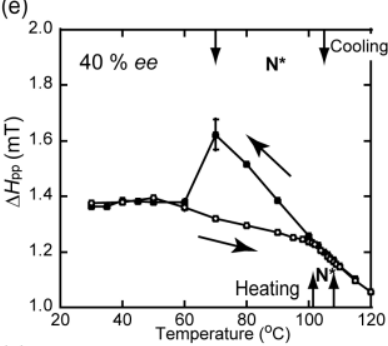

(g)
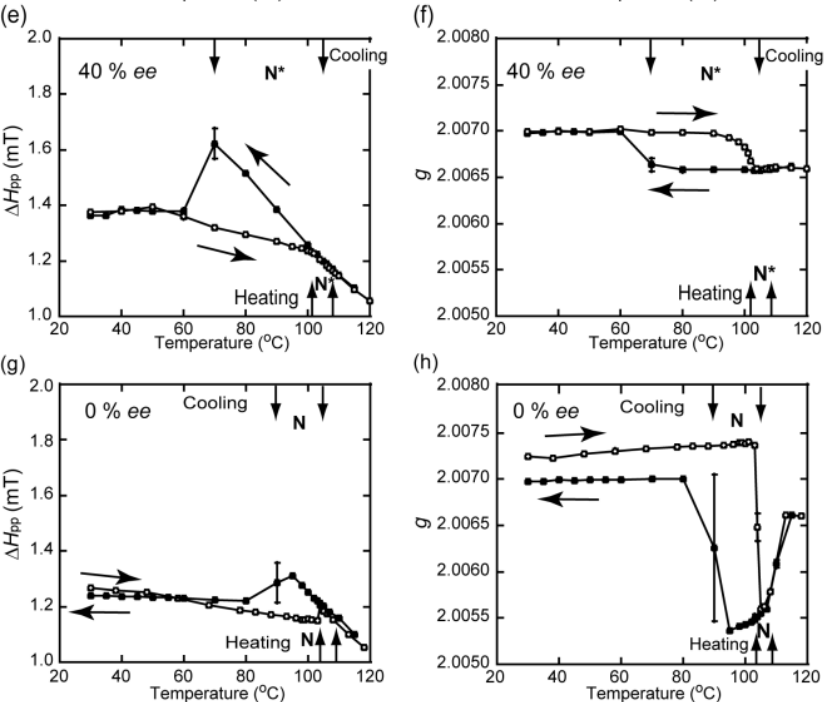

(h)

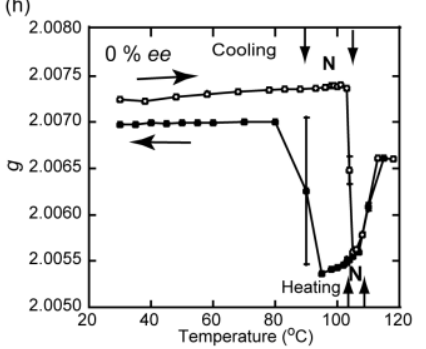

Fig. 10 Temperature dependence of $\Delta H_{\mathrm{pp}}$ and $g$ values for $\mathbf{2 a}$ at a magnetic field of $0.33 \mathrm{~T}$. (a,b) $(2 S, 5 S)-2 \mathrm{a}(96 \% e e),(\mathrm{c}, \mathrm{d})$ $(2 S, 5 S)-\mathbf{2 a}(60 \% e e),(\mathrm{e}, \mathrm{f})(2 S, 5 S)-\mathbf{2 a}(40 \% e e)$, and $(\mathrm{g}, \mathrm{h})( \pm)-$ 2a. The LC temperatures determined by DSC analysis in the heating and cooling runs are shown in the lower and upper sides inside panels, respectively. 
magneto-LC effects. As expected, the difference in the $\chi_{\text {rel }}$ value of these three magnetic LC phases at $75^{\circ} \mathrm{C}$ on the cooling run was consistent with that in the response to the action of a permanent magnet in the increasing order of $\mathrm{N} \ll \mathrm{N}^{*}<\mathrm{SmA}^{*}$ (Fig. 5 and 8), 5 although the $\mathrm{N}$ droplet was partially crystallized on water.

\section{Origin of Magneto-LC Effects}

In our previous paper, it was proved that the generation of 10 positive magneto-LC effects has nothing to do with the molecular reorientation effect arising from the magnetic anisotropy $(\Delta \chi){ }^{12}$ To gain an insight into the origin of the negative or positive magneto-LC effects $(\bar{J}<0$ or $\bar{J}>0$ ) operating in the $\mathrm{N}$ and doped-N* phases of $( \pm)-\mathbf{2} \mathbf{a}$ or in the $\mathrm{N}^{*}$ phase of $(2 S, 5 S)-\mathbf{2} \mathbf{a}$ and ${ }_{15} \mathrm{SmA}^{*}$ phase of $(2 S, 5 S)-\mathbf{2} \mathbf{b}$, respectively, the temperature dependence of $\Delta H_{\mathrm{pp}}$ and $g$ values was compared with that of $\chi_{\text {rel }}$ for these samples (Fig. 5, 7, 8, 10, and 11). This is because 1) the change in $\Delta H_{\mathrm{pp}}$ reflects the following two competing factors, (a) spin-spin dipole interaction (the stronger the interaction is, the 20 more the $\Delta H_{\mathrm{pp}}$ increase is) and (b) spin-spin exchange interaction (the stronger the interaction is, the more the $\Delta H_{\mathrm{pp}}$ decrease is) and 2) the change in $g$ value corresponds to that in the molecular (a)
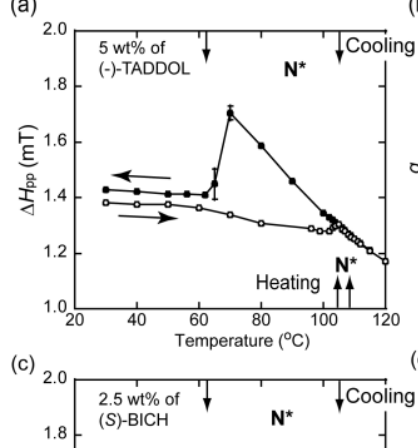

(b)

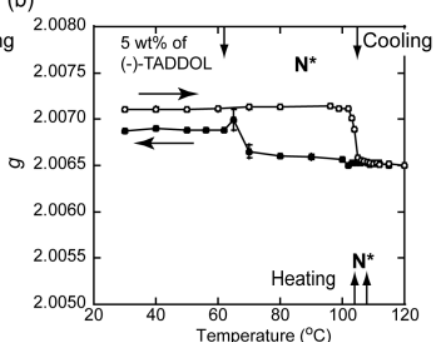

(d)

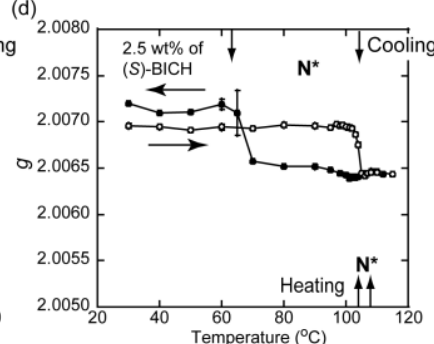

(e)
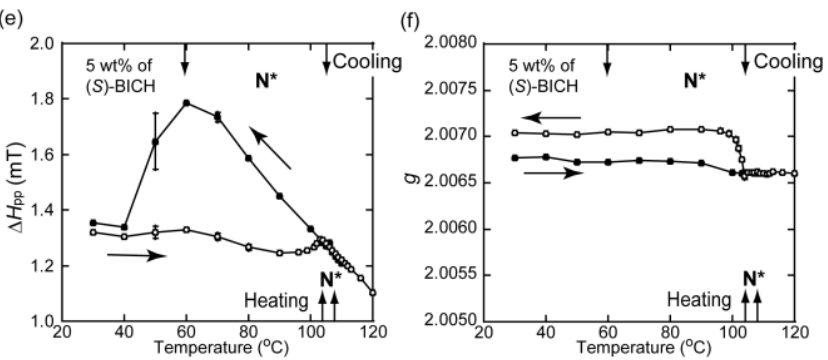

Fig. 11 Temperature dependence of $\Delta H_{\mathrm{pp}}$ and $g$ values for $( \pm)-2 \mathbf{a}$ in the presence of a chiral dopant at a magnetic field of $0.33 \mathrm{~T}$. (a,b) $5 \mathrm{wt} \%$ of (-)-TADDOL, (c,d) $2.5 \mathrm{wt} \%$ of $(S)$ $\mathrm{BICH}$, and (e,f) $4.0 \mathrm{wt} \%$ of $(S)-\mathrm{BICH}$. The LC temperatures determined by DSC analysis in the heating and cooling runs are shown in the lower and upper sides inside panels, respectively. orientation in the magnetic field.

In the case of $( \pm)-\mathbf{2} \mathbf{a}$, a slight increase in $\Delta H_{\mathrm{pp}}$ occurred in ${ }_{25}$ concert with the slight decrease in $\chi_{\text {rel }}$ at the Cr-to-N transition in the heating run, irrespective of the presence of chiral dopants and the $g$ value change (Fig. 5d, 7, 10g,h, and 11), indicating the increase of spin-spin dipole interactions in both the $\mathrm{N}$ and chiral dopant-induced $\mathrm{N}^{*}$ phases of $( \pm)-\mathbf{2 a}$. Accordingly, it is quite 30 natural to consider that the negative magneto-LC effects operating in the $\mathrm{N}$ phase of $( \pm)-\mathbf{2} \mathbf{a}$ originate from the generation of antiferromagnetic interactions due to the local SOMO-SOMO overlapping in the strong $R S$ magnetic dipolar interaction in which the side-by-side spin-spin dipole interaction should operate 35 (Fig. 12a,b).

In contrast, at the Cr-to- $\mathrm{N}^{*}$ transition of $(2 S, 5 S)-\mathbf{2 a}(96 \%$ ee), both $\Delta H_{\mathrm{pp}}$ and $\chi_{\text {rel }}$ distinctly increased without no molecular reorientation in the magnetic field (Fig. 5a and 10a,b), reflecting the generation of the energetically favored ferromagnetic head-to40 tail spin-spin dipole interactions (Fig. 12c), as observed in the $\mathrm{N}^{*}$ phase of 1.12

In the case of $(2 S, 5 S)-\mathbf{2 b}(89 \% e e)$, the large $g$ value (2.0069) in the $\mathrm{SmA}^{*}$ phase having a large LC domain size formed by cooling from the isotropic phase indicates that the majority of 45 molecular long axes aligned perpendicular to the magnetic field (Fig. 8c). In harmony with this behavior, the substantial $\chi_{\text {rel }}$ increase occurred in the $\mathrm{SmA}^{*}$ phase with a deeply interdigitated layer structure, together with a slight $\Delta H_{\mathrm{pp}}$ decrease due to the (a)

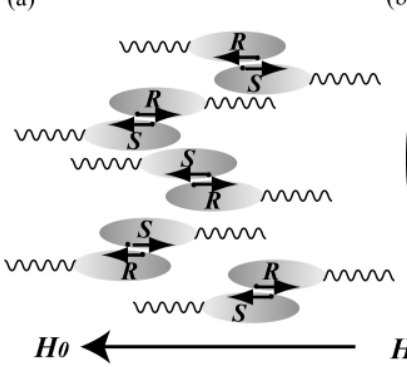

(c)

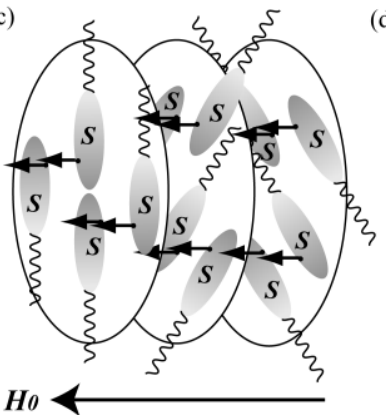

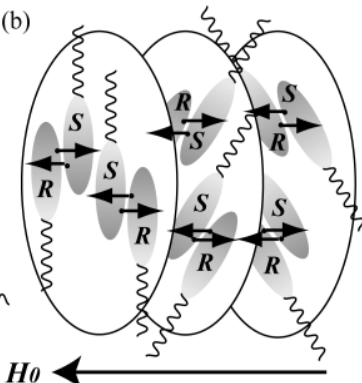

(d)

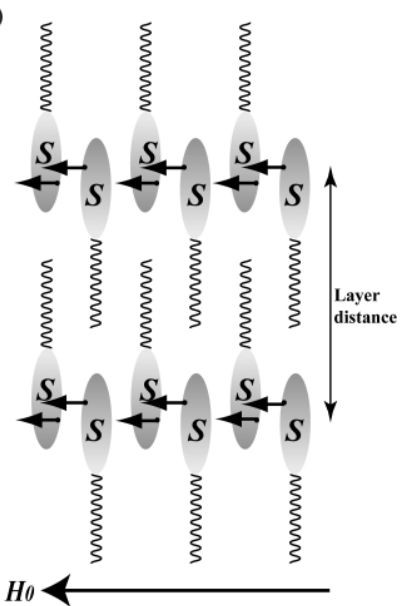

Fig. 12 Schematic illustration of spin-spin dipole interactions in LC phases. (a) $\mathrm{N}$ phase of ( \pm )-2a, (b) $\mathrm{N}^{*}$ phase of ( \pm )-2a with a chiral dopant, (c) $\mathrm{N}^{*}$ phase of $(2 S, 5 S)-\mathbf{2 a}$, and (d) SmA* phase of $(2 S, 5 S)-\mathbf{2 b}$. 
increased spin-spin exchange interactions (Fig. 8a,b). Therefore, in the $\mathrm{SmA}^{*}$ phase, ferromagnetic head-to-tail spin-spin dipole interactions should dominate, too (Fig. 12d).

\section{${ }_{5}$ Conclusions}

Chiral all-organic LC nitroxide radical compounds 2 with a positive dielectric anisotropy $(\Delta \varepsilon>0)$ showing a chiral $\mathrm{N}^{*}$ or $\mathrm{SmA}^{*}$ phase, or an achiral $\mathrm{N}$ phase exhibited unique magnetic 10 behaviors which are different from those of LC compounds 1 with a negative dielectric anisotropy $(\Delta \varepsilon<0)$ displaying chiral $\mathrm{N}^{*}$ and/or SmC* phases, or achiral $\mathrm{N}$ and/or SmC phases. ${ }^{12}$ Under weak magnetic fields, larger positive magneto-LC effects $(\bar{J}>0)$ operated in the $\mathrm{SmA}^{*}$ phase of $(2 S, 5 S)-\mathbf{2} \mathbf{b}$ than in the $\mathrm{N}^{*}$ 15 phase of $(2 S, 5 S)-\mathbf{2 a}$, while small negative magneto-LC effects $(\bar{J}<0)$ were observed in the $\mathrm{N}$ phase of $( \pm)-\mathbf{2 a}$, which was in contrast to the $\mathrm{N}$ phase of $( \pm)-\mathbf{1}$ showing positive magneto-LC effects $(\bar{J}>0)$. The origin of such negative magneto-LC effects operating in the $\mathrm{N}$ phase of $( \pm)-\mathbf{2} \mathbf{a}$ was interpreted in terms of the 20 generation of antiferromagnetic interactions which is associated with the formation of the $R S$ magnetic dipolar interaction due to the strong electric dipole interactions. Therefore, although addition of chiral dopants to the $\mathrm{N}$ phase resulted in the formation of the racemic $\mathrm{N}^{*}$ phase of $\mathbf{2 a}$, the sign and magnitude of the 25 magneto-LC effects did not change. These experimental results strongly suggest that positive magneto-LC effects could be induced in discotic magnetic LC phases ${ }^{15,16}$ by introducing chirality into the molecules so as to avoid the discotic dimer formation.

30 Furthermore, among the bulk $\mathrm{N}^{*}, \mathrm{SmC}^{*}, \mathrm{SmA}^{*}, \mathrm{~N}$, and $\mathrm{SmC}$ phases of all-organic LC nitroxide radical compounds (1 and 2) which we have prepared thus far, the $\mathrm{SmA}^{*}$ phase of $(2 S, 5 S)-\mathbf{2 b}$ displayed the largest positive magneto-LC effects $(\bar{J}>0)$. Moreover, it should be emphasized that VT-EPR spectroscopy is 35 an excellent means to analyze the magnetic interactions operating in the LC phases of all-organic nitroxide radical compounds.

\section{Acknowledgement}

This work was supported by the Grants-in-Aid for Scientific ${ }_{40}$ Research (No. 23245008 and 23655127) from Japan Society for the Promotion of Science (JSPS). K.S. and Y.U. are grateful to the JSPS Research Fellowships for Young Scientists. We thank DIC corporation for generous gift of $(S)-\mathrm{BICH}$.

\section{Notes and references}

45 Graduate School of Human and Environmental Studies, Kyoto University, Kyoto, 606-8501, Japan. E-mail: tamurarui@ hes.mbox.media.kyotou.ac.jp; Fax: +81 75-753-7915; Tel:+81 75-753-6815

$\dagger$ Electronic supplementary information (ESI) available: Preparation of 2; HPLC charts and XRD patterns for $(2 S, 5 S)-\mathbf{2 a},( \pm)-\mathbf{2 a},(2 S, 5 S)-\mathbf{2 b}$ and

$50( \pm)-\mathbf{2 b}$; selected EPR spectra and temperature dependence of $\chi_{\mathrm{M}}$ and $\chi_{\text {para }}$ $T$ for $(2 S, 5 S)-\mathbf{2 a},( \pm)-\mathbf{2} \mathbf{a}$ and $(2 S, 5 S)-\mathbf{2} \mathbf{b}$; polarized optical micrographs of 2a in a wedge cell; movies of the motion of LC droplets on water for $(2 S, 5 S)-\mathbf{2 a},( \pm)-\mathbf{2 a}$ and $(2 S, 5 S)-\mathbf{2 b}$. See DOI: $10.1039 / \mathrm{b} \# \# \# \# \# \mathbf{x}$
551 S. Chamdrasekhar (ed), Liquid Crystal Second Edition, Cambridge University Press, Cambridge, 1992.

2 I. Dierking, Textures of Liquid Crystals, Wiley-VCH, Weinheim , 2003.

3 L. M. Bilinov, Electro-Optical and Magneto-Optical Properties of 60 Liquid Crystals, John Wiley \& Sons, New York, 1983.

4 D. Demus, J. Goodby, G. W. Gray, H.-W. Spiess, V. Vill (ed), Physical Properties of Liquid Crystals, Wiley-VCH, Weinheim, 1999.

5 P. Kaszynski, in Magnetic properties of Organic Molecules, ed. P. M. 65 Lahti, Marcel Dekker, New York, 1999, ch. 15, pp. 305-324.

6 K. Griesar and W. Haase, in Magnetic Properties of Organic Molecules, ed. P. M. Lahti, Marcel Dekker, New York, 1999, ch. 16, pp. 325-344.

7 J.-L. Serrano, Metallomesogens: Synthesis, Properties, and 70 Applications, VCH, Weinheim, 1996.

8 R. Tamura in Nitroxide: Applications in Chemistry, Biochemistry, and Materials Science, ed. G. I. Likhtensthtein, J. Yamauchi, S. Nakatsuji, A. I. Smirnov, R. Tamura, Wiley-VCH, Weinheim, 2008 , ch. 9, pp. 303-329.

759 R. Tamura, N. Ikuma, S. Shimono, in Soft Nanomaterials, ed. H. S. Nalwa, American Scientific Publishers, USA, 2009, Vol. 1, pp. $257-$ 277.

10 R. Tamura, Y. Uchida, K. Suzuki, in Liquid Crystals Beyond 80 Displays: Chemistry, Physics, and Applications, ed. Q. Li, John Wiley \& Sons, New York, chap.3, in press.

11 R. Tamura, Y. Uchida, N. Ikuma, J. Mater. Chem., 2008, 18, $2872-$ 2876.

8512 Y. Uchida, K. Suzuki, R. Tamura, N. Ikuma, S. Shimono, Y. Noda, J. Yamauchi, J. Am. Chem. Soc., 2010, 132, 9746-9752; Y. Uchida, N. Ikuma, R. Tamura, S. Shimono, Y. Noda, J. Yamauchi, Y. Aoki, H. Nohira, J. Mater. Chem., 2008, 18, 2950-2952.

13 M. Seredyuk, A. B. Gaspar, V. Ksenofontov, Y. Galyametdinov, J. 90 Kusz, and P. Gütlich, Ad. Funct. Mater., 2008, 18, 2089-2101; Y. G. Galyametdinov, W. Haase, B. Goderis, D. Moors, K. Driesen, R. Van Deun, and K. Binnemans, J. Phys. Chem. B, 2007, 111, 13881138815; Y. G. Galyametdinov, W. Haase, L. Malykhina, A. Prosvirin, I. Bikchantaev, A. Rakhmatullin, and K. Binnemans, Chem. Eur. J., 2001, 7, 99-105; K. Binnemans, Y. G. Galyametdinov, R. Van Deun, D. W. Bruce, S. R. Collinson, A. P. Polishchuk, I. Bikchantaev, W. Haase, A. V. Prosvirin, L. Tinchurina, I. Litvinov, A. Gubajdullin, A. Rakhmatullin, K. Uytterhoeven, and L. Van Meervelt, J. Am. Chem. Soc., 2000, 122, 4335-4344; V. S. Mironov, Y. G. Galyametdinov, A. Ceulemans, and K. Binnemans, J. Chem. Phys., 2000, 113, 10293-10303; Y. Galyametdinov, M. a Athanassopoulou, K. Griesar, O. Kharitonova, E. a Soto Bustamante, L. Tinchurina, I. Ovchinnikov, and W. Haase, Chem. Mater., 1996, 8, 922-926; W. Haase, K. Griesar, E. A. Soto Bustmante and Y. Galyametdinov, Mol. Cryst. Liq. Cryst., 1995, 274, 99-101; K. Griesar, Y. Galyametdinov, M. Athanassopoulou, I. Ovchinnikov, W. Haase, Adv. Mater. 1994, 6, 381-384.

14 S. Nakatsuji, M. Mizumoto, H. Ikemoto, H. Akutsu and J. Yamada, Eur. J. Org. Chem., 2002, 1912-1918; J. Allgaieer and H. Finkelmann, Macromol. Chem. Phys., 1994, 195, 1017-1030; M. Dvolaitzky, C. Taupin and F. Polydy, Tetrahedron Lett., 1976, 1469-1672; M. Dvolaitzky, J. Billard and F. Poldy, Tetrahedron, 
1976, 32, 1835-1838; M. Dvolaitzky, J. Billard and F. Poldy, C. R. Hebd. Seances Acad. Sci., Ser. C, 1974, 279, 533-535.

15 C. V. Yelamaggad, A. S. Achalkumar, D. S. S. Rao, M. Nobusawa, H. Akutsu, J.-ichi Yamada, and S. Nakatsuji, J. Mater. Chem., 2008, 18, 3433-3437.

16 S. Castellanos, F. López-Calahorra, E. Brillas, L. Juliá, and D. Velasco, Angew. Chem. Int. Ed., 2009, 48, 6516-6519.

17 N. Ikuma, R. Tamura, S. Shimono, N. Kawame, O. Tamada, N. Sakai, J. Yamauchi, and Y. Yamamoto, Angew. Chem. Int. Ed., 2004, 43,

10 3677-3682; N. Ikuma, R. Tamura, S. Shimono, Y. Uchida, K. Masaki, J. Yamauchi, Y. Aoki, and H. Nohira, Adv. Mater., 2006, 18, 477-480; N. Ikuma, R. Tamura, K. Masaki, Y. Uchida, S. Shimono, J. Yamauchi, Y. Aoki, and H. Nohira, Ferroelectrics, 2006, 343, 119-125.

1518 F. Bloch, Phys. Rev., 1946, 70, 460-474.

19 Y. Uchida, R. Tamura, N. Ikuma, S. Shimono, J. Yamauchi, Y. Shimbo, H. Takezoe, Y. Aoki, H. Nohira, J. Mater. Chem., 2009, 19, 415-418.

20 H. J. Müller, W. Haase, J. Phys. (Paris), 1983, 44, 1209-1213. 